\title{
SFRP5 serves a beneficial role in arterial aging by inhibiting the proliferation, migration and inflammation of smooth muscle cells
}

\author{
JIADELA TELIEWUBAI*, HONGWEI JI*, YUYAN LU, BIN BAI, \\ SHIKAI YU, CHEN CHI, YAWEI XU and YI ZHANG \\ Department of Cardiology, Shanghai Tenth People's Hospital, \\ Tongji University School of Medicine, Shanghai 200072, P.R. China
}

Received November 24, 2017; Accepted July 17, 2018

DOI: $10.3892 / \mathrm{mmr} .2018 .9467$

\begin{abstract}
Secreted frizzled-related protein 5 (SFRP5) is one of the anti-inflammatory adipokines secreted from white adipose tissue. However, little is known about the effect of SFRP5 on the cardiovascular system. The aim of the present study was to determine the effect of SFRP5 on smooth muscle cell (SMC) proliferation, migration and inflammation. The plasma levels of SFRP5 were evaluated in a cohort-based elderly population using ELISA, and the expression of SFRP5 in Sprague-Dawley rat aortas was detected using immunohistochemistry. SMC proliferation and migration were evaluated in vitro using 5-ethynyl-2'-deoxyuridine cell proliferation and wound-healing assays, respectively, while reactive oxygen species (ROS) production and cell signaling were assessed using a 2',7'-dichlorodihydrofluorescein diacetate assay and immunoblotting, respectively. The results revealed that plasma levels of SFRP5 were positively correlated with age in the elderly Chinese cohort. Similarly, aorta SFRP5 expression was significantly higher in 15-month-old rats compared with 6-month-old rats. In vitro, SFRP5 significantly inhibited rat aortic SMC proliferation and migration that were induced by platelet-derived growth factor (PDGF)-BB, as well as inhibiting ROS generation. Compared with the effect of PDGF-BB on SMCs, SFRP5 at 100 and $200 \mathrm{ng} / \mathrm{ml}$ significantly decreased SMC proliferation by 31.5 and $34.8 \%$, respectively $(\mathrm{P}<0.05)$. SFRP5 at 100 and $200 \mathrm{ng} / \mathrm{ml}$ also inhibited the migration of SMCs by 24.9 and $28.4 \%$, respectively, when compared with the effects of PDGF-BB. SFRP5 attenuated the PDGF-BB-induced expression of $\beta$-catenin and proliferating cell nuclear antigen, while p38 phosphorylation
\end{abstract}

Correspondence to: Dr Yi Zhang, Department of Cardiology, Shanghai Tenth People's Hospital, Tongji University School of Medicine, 301 Yanchang Middle Road, Shanghai 200072, P.R. China E-mail: yizshcn@gmail.com

*Contributed equally

Key words: secreted frizzled-related protein 5, arterial aging, smooth muscle cell, Wnt//-catenin pathway, p38 was significantly attenuated. Together, the present results suggested that SFRP5 may inhibit SMC proliferation, migration and inflammation by suppressing the Wnt/ $\beta$-catenin and p38/mitogen-activated protein kinase signaling pathways.

\section{Introduction}

Aging is a major risk factor for the development of cardiovascular diseases, and it has been estimated that $20 \%$ of the world's population will be $>65$ years old by 2030 (1). With medical advances, the life expectancy of humans has increased remarkably; however, this increase is coincident with the increased morbidity and mortality of age-related diseases, including cardiovascular aging. Aged vessels undergo biochemical, histological and structural alterations, including inflammation, arterial thickening and arterial stiffening. Vascular smooth muscle cells (SMCs) are the most abundant cell type in the medial layer of arteries and serve an important role in aging-induced vascular dysfunction, including increased cell proliferation, migration and inflammation (2).

The number of studies investigating perivascular adipose tissue in vascular function and associated diseases has increased in recent years. Adipokines secreted from perivascular adipose tissue directly regulate vascular function through paracrine and endocrine effects on the vascular wall (3), and participate in the inflammatory response, vascular remodeling, proliferation and migration of SMCs (4). The majority of adipokines are pro-inflammatory, including leptin, visfatin and resistin, while few are anti-inflammatory, such as adiponectin (4). Secreted frizzled-related protein 5 (SFRP5) is a novel anti-inflammatory adipokine of the SFRP family (5). It has been implicated in adipogenesis, although its role in obesity remains controversial $(5,6)$. Ouchi et al $(5)$ reported that SFRP5 expression was increased in wild-type mice upon administration of a high-fat/high-sucrose diet for 12 weeks, while SFRP5 expression was downregulated after 24 weeks, indicating more severe metabolic dysfunction. However, other studies have reported that SFRP5 expression is upregulated in white adipose tissue in diet-induced obesity (6,7). A number of previous studies have reported that SFRP5 inhibits inflammation, attenuates hepatic stellate cell proliferation and suppresses smooth muscle calcification via canonical and non-canonical Wnt signaling $(8,9)$. Furthermore, recent studies have investigating the association 
between SFRP5 and cardiovascular disease revealed that low SFRP5 levels may contribute to the development of coronary artery disease (10), and that SFRP5 antagonizes inflammatory responses in the heart following ischemia/reperfusion (11). However, the role of SFRP5 in aged arteries remains unclear. The aim of the present study was to investigate the role of SFRP5 on SMCs in vascular aging.

\section{Materials and methods}

Patients. Plasma SFRP5 levels were measured in blood samples from participants in the Northern Shanghai Study, which is an ongoing community-based prospective study. Written informed consent was obtained from all participants. The present study was approved by the Shanghai Tenth People's Hospital Ethics Committee (Shanghai, China). Briefly, 1,745 participants aged $>65$ years were enrolled in the present study. Venous blood samples were obtained from the subjects after fasting overnight. The study followed a previously published protocol (12).

Animals. All animal procedures were carried out humanely in adherence with the animal experimental guidelines approved by the Animal Care and Use Committee of Shanghai Tenth People's Hospital (Shanghai, China). For immunohistochemical staining, 12 Sprague-Dawley (SD) rats were randomly divided into two groups and sacrificed after 6 or 15 months. SD rats aged 6-8 weeks were used for SMC culture.

Cell culture. SMCs were isolated from the thoracic aorta of 6-8-week-old male SD rats. The aorta was obtained aseptically by digestion method (13). Cells were cultured in Dulbecco's modified Eagle's medium (Gibco; Thermo Fisher Scientific, Inc., Waltham, MA, USA) supplemented with $20 \%$ fetal bovine serum (FBS; Gibco; Thermo Fisher Scientific, Inc.) and $1 \%$ penicillin/streptomycin at $37^{\circ} \mathrm{C}$ with $5 \% \mathrm{CO}_{2}$. Cells between passage 2 and 7 were used in subsequent experiments and cultured in $0.4 \%$ FBS for 24 -h serum starvation prior to the experiments.

Enzyme-linked immunosorbent assay (ELISA). Plasma was isolated and stored at $-80^{\circ} \mathrm{C}$. Plasma SFRP5 levels were measured using ELISA according to the manufacturer's protocol (Human sFRP-5 DuoSet ELISA; R\&D Systems, Inc., Minneapolis, MN, USA). Briefly, microtiter plates were coated with diluted mouse anti-human SFRP5 capture antibody and sealed. After overnight incubation at room temperature, each well was washed with washing buffer (PBS containing 0.05\% Tween 20). Next, $300 \mu 1$ Reagent Diluent Concentrate [1\% bovine serum albumin (BSA) in PBS; $\mathrm{pH}, 7.2-7.4 ; 0.2-\mu \mathrm{m}$ filtered] was added to each well and incubated at room temperature for $2 \mathrm{~h}$. Upon washing the plates three times with washing buffer, $100 \mu \mathrm{l}$ sample or standards in Reagent Diluent Concentrate was added per well and incubated for $2 \mathrm{~h}$ at room temperature. Next, $100 \mu \mathrm{l}$ diluted biotinylated sheep anti-human SFRP5 detection antibody was added to each well and incubated for $2 \mathrm{~h}$ at room temperature. Following three washes, $100 \mu$ l working dilution of streptavidin-horseradish peroxidase B was added to each well, and the plate was incubated for $20 \mathrm{~min}$ at room temperature. $100 \mu \mathrm{l}$ substrate solution was added to each well for $20 \mathrm{~min}$ at room temperature, following which $50 \mu \mathrm{l}$ stop solution was added to each well. The optical density of each well at $450 \mathrm{~nm}$ was immediately determined using a microplate reader.

Immunohistochemistry. Thoracic aortas were obtained from rats and fixed in $10 \%$ formalin. The aortic segments were then dehydrated in a graded ethanol series, dewaxed with xylene and embedded in paraffin wax. Upon paraffin embedding, $5-\mu \mathrm{m}$ sections were cut. The endogenous peroxidase activity was blocked with $0.3 \% \mathrm{H}_{2} \mathrm{O}_{2}$ in PBS for 10 min, and slides were blocked with $2 \%$ BSA following antigen retrieval. Next, slides were incubated with rabbit polyclonal anti-SFRP5 antibody (dilution 1:100; GeneTex, Inc., Irvine, CA, USA) overnight at $4^{\circ} \mathrm{C}$, followed by exposure to the secondary antibody at room temperature for $1 \mathrm{~h}$ and incubation with 3 '-diaminobenzidine substrate for 1-3 min. The specimens were counterstained with hematoxylin and images were recorded using a Leica DMI6000 microscope (Leica Microsystems, Inc., Buffalo Grove, IL, USA).

Cell proliferation. SMC proliferation was determined using a 5-ethynyl-2'-deoxyuridine (EdU) cell proliferation assay (Invitrogen; Thermo Fisher Scientific, Inc.). Cells were seeded on 12 -well plates at a density of $1 \times 10^{4}$ cells $/ \mathrm{ml}$. Cells were pretreated with $0,10,50,100$ or $200 \mathrm{ng} / \mathrm{ml}$ recombinant mouse SFRP5 (R\&D Systems, Inc.) for $24 \mathrm{~h}$ prior to stimulation with platelet-derived growth factor (PDGF)-BB (20 ng/ml; R\&D Systems, Inc.). Cells without SFRP5 or PDGF-BB were used as negative controls, while cells treated only with PDGF-BB were used as positive controls. $\mathrm{EdU}(10 \mu \mathrm{M})$ was added to each well for $10 \mathrm{~h}$, and cells were detected using the Click-iT cell reaction cocktail (Thermo Fisher Scientific, Inc.) according to manufacturer's instructions. Cells were counterstained with Hoechst 33342 solution ( $5 \mu \mathrm{g} / \mathrm{ml}$ diluted in PBS) for nuclear staining. The stained cells were examined under an Olympus IX83 microscope (Olympus Corporation, Tokyo, Japan) and images were captured.

Wound-healing assay. The effect of SFRP5 on SMC migration was evaluated using a wound-healing assay. Cells were seeded in a 6 -well culture plate at a concentration of $1 \times 10^{6}$ cells $/ \mathrm{ml}$ and incubated until 90-100\% confluence was reached. Cells were pretreated with $0,10,50,100$ or $200 \mathrm{ng} / \mathrm{ml}$ recombinant mouse SFRP5 for $24 \mathrm{~h}$ and a sterile pipette tip was used to create a wound of $\sim 5 \mathrm{~mm}$ in each well. PDGF-BB $(20 \mathrm{ng} / \mathrm{ml})$ was added to the wells and cells without SFRP5 or PDGF-BB were used as negative controls. Images were captured at 0 , 12, 24 and $36 \mathrm{~h}$ after wounding. The area of migration was calculated as the difference between the initial area $\left(\mathrm{S}_{0}\right)$ and the area measured at each time $\left(\mathrm{S}_{t}\right)$, while the migration rate was defined as the migrated area divided by the initial area: Migration rate $=\left(\mathrm{S}_{0}-\mathrm{S}_{\mathrm{t}}\right) / \mathrm{S}_{0}$.

Estimation of ROS generation. Intercellular reactive oxygen species (ROS) generation was assessed using 2',7'-diclorofluorescein diacetate $\left(\mathrm{H}_{2} \mathrm{DCFDA}\right.$; Invitrogen; Thermo Fisher Scientific, Inc.). SMCs were pretreated with SFRP5 for $48 \mathrm{~h}$, followed by incubation with $\mathrm{H}_{2} \mathrm{O}_{2}(1.0 \mathrm{mM})$ for $30 \mathrm{~min}$ and additional incubation with $\mathrm{H}_{2}$ DCFDA (10 mM) for $30 \mathrm{~min}$. Cells were subsequently subjected to flow cytometry 

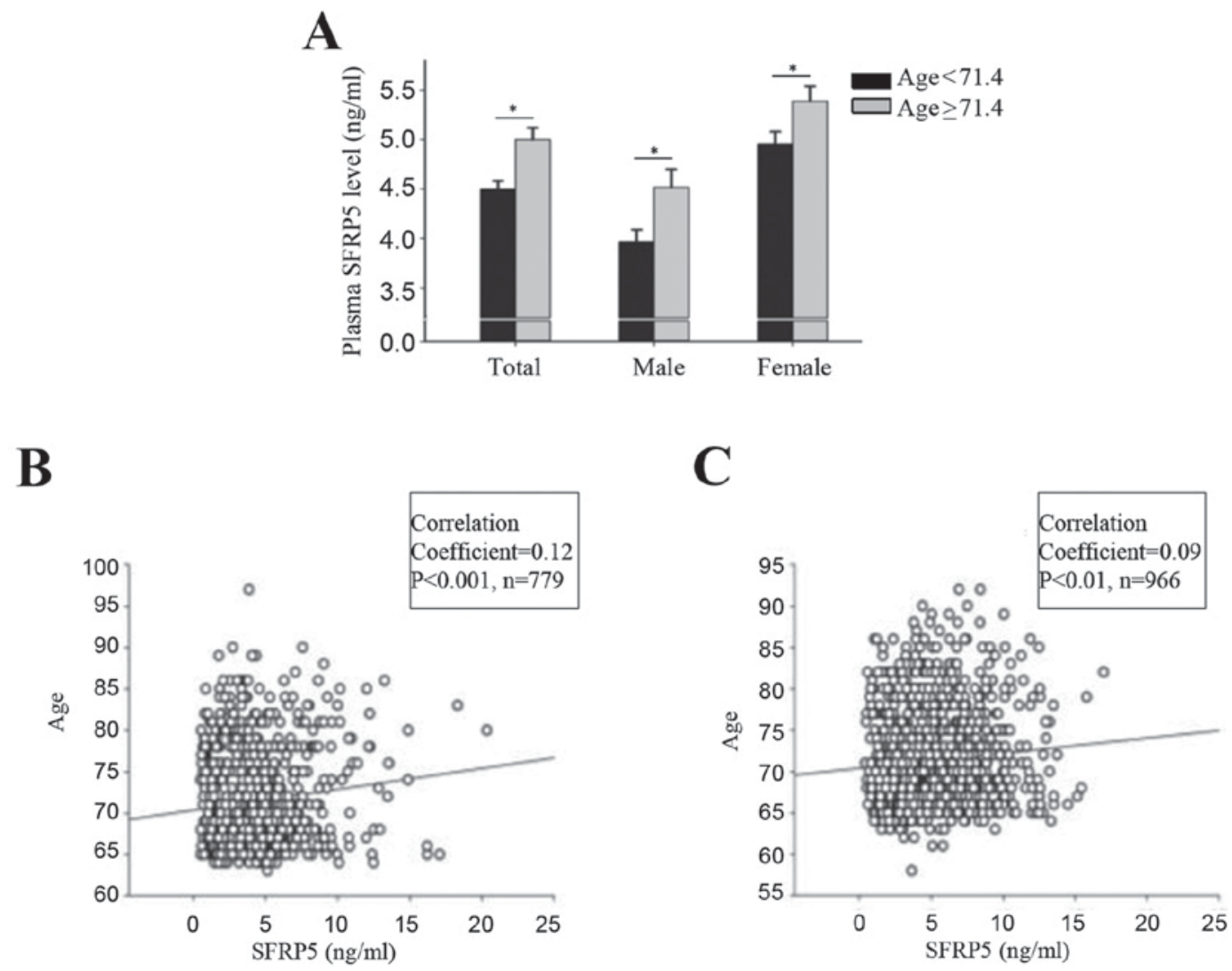

Figure 1. Correlation between age and SFRP5 expression. (A) Plasma SFRP5 increased with age in an elderly community. ${ }^{*} \mathrm{P}<0.05$, as indicated. (B and C) Scatter plots showing the correlation between SFRP5 expression and age in (B) males and (C) females. SFRP5, secreted frizzled-related protein 5.

(FACSCalibur; BD Biosciences, San Jose, CA, USA), using an excitation wavelength of $488 \mathrm{~nm}$ and an emission wavelength of $528 \mathrm{~nm}$. The ROS generation rate was expressed as the ratio of fluorescence-positive cells divided by the total number of cells.

Western blot analysis. SMCs pretreated with different concentrations of SFRP5 were co-incubated with $20 \mathrm{ng} / \mathrm{ml}$ PDGF-BB prior to being harvested. Total protein was extracted from these SMCs using a lysis buffer (Cell Signaling Technology, Inc., Danvers, MA, USA). The protein concentration was determined using a BCA Protein Assay kit (Beyotime Institute of Biotechnology, Shanghai, China) following the manufacturer's instructions. Equal quantities of protein from each sample were separated by $8-12 \%$ SDS-PAGE and transferred onto a nitrocellulose membrane. Membranes were blocked with 5\% BSA in PBS-Tween 20 for $1 \mathrm{~h}$ prior to overnight incubation with the primary antibodies. The primary antibodies used were diluted as follows: Anti- $\beta$-actin (1:2,000; Cell Signaling Technology, Inc.), anti-proliferating cell nuclear antigen (PCNA) (1:400; Abcam, Cambridge, UK), anti-cyclin D1 (1:1,000; Cell Signaling Technology, Inc.), anti- $\beta$-catenin (1:600; Abcam) and anti-total and anti-phosphorylated extracellular signal-regulated kinase (ERK)1/2, c-Jun N-terminal kinase (JNK) and p38 (all 1:1,000; Cell Signaling Technology, Inc.). Membranes were then incubated with secondary antibodies at room temperature for $60 \mathrm{~min}$. The membranes were visualized using an Amersham Imager 600 system (GE Healthcare Life Sciences, Little Chalfont, UK) and enhanced chemiluminescence (GE Healthcare Life Sciences). Quantitative analysis of the western blot bands was achieved using ImageJ software (National Institutes of Health, Bethesda, MD, USA).

Statistical analysis. Each experiment was performed at least three times. The results are expressed as the mean \pm standard error of the mean. Differences between multiple groups were determined using one-way analysis of variance and a least significant difference post hoc test. Two-sided $\mathrm{P}<0.05$ was considered to indicate a statistically significant difference. All statistical analyses were performed using SPSS software v.20.0 (IBM Corp., Armonk, NY, USA).

\section{Results}

Plasma SFRP5 levels increase with age. The mean age of the participants in the Northern Shanghai Study was $71.4 \pm 0.14$ years $(71.4 \pm 0.21$ years for males and $71.4 \pm 0.19$ years for females). The mean plasma SFRP5 was $4.7 \pm 0.07$ (4.2 \pm 0.10 for males and 5.2 \pm 0.09 for females). Correlation analysis indicated that levels of plasma SFRP5 were significantly and positively correlated with age for males $(\mathrm{r}=0.12 ; \mathrm{P}<0.001)$ and females $(\mathrm{r}=0.09 ; \mathrm{P}<0.01)$ (Fig. 1). Participants were divided into two groups based on their age ( $<71.4$ years and $\geq 71.4$ years) and into subgroups based on sex. Significant differences in plasma SFRP5 level were observed between the two groups, both in the total population and in the sex subgroups $(\mathrm{P}<0.001$; Fig. 1$)$.

SFRP5 expression in rat aortas. Immunohistochemical staining revealed that the expression of SFRP5 in the thoracic 

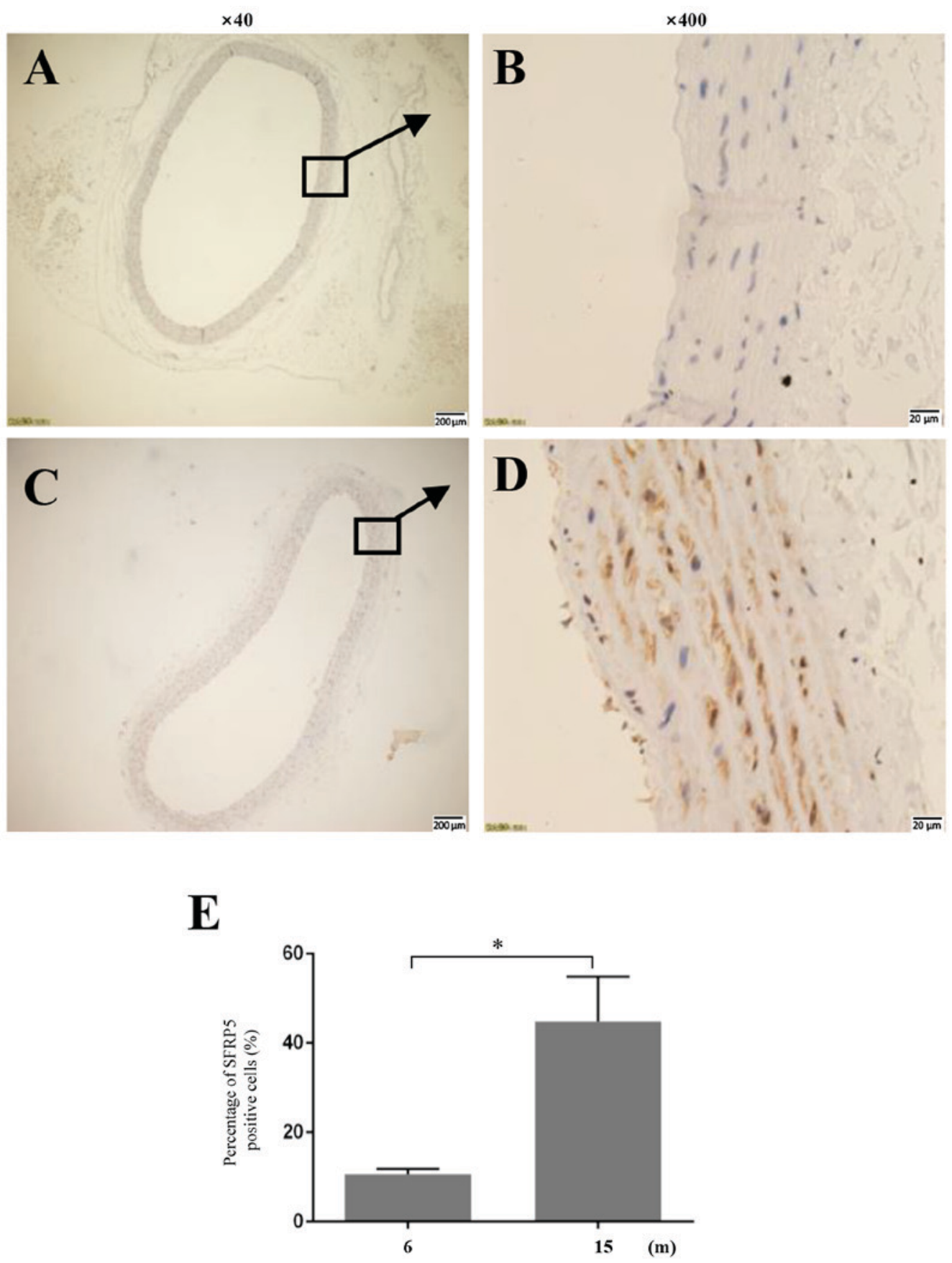

Figure 2. SFRP5 expression in rat aortas. Immunohistochemical staining of SFRP5 in (A and B) 6-month-old rat aortas and (C and D) 15-month-old rat aortas. Magnification, $\mathrm{x} 40$ and $\mathrm{x} 400$, as indicated. (E) Quantitative analysis of SFRP5 expression in 6- and 15-month-old rat aortas. "P $<0.05$, as indicated. m, month; SFRP5, secreted frizzled-related protein 5 .

aorta of 15-month-old rats was significantly higher compared with 6-month-old rats (Fig. 2).

SFRP5 inhibits PDGF-BB-induced SMC proliferation and migration. PDGF-BB has previously been reported to increase the proliferation and migration of SMCs (14), and so cells treated with PDGF-BB in the present study served as positive controls. As shown in Fig. 3, 20 ng/ml PDGF-BB significantly increased the proliferation of SMCs compared with the control group $(10.3 \pm 0.18 \%$ vs. $3.0 \pm 0.37 \%$, respectively; $\mathrm{P}<0.01)$. Pretreatment with recombinant SFRP5 significantly inhibited PDGF-BB-induced cell proliferation. Compared with the PDGF-BB group, cell proliferation decreased with recombinant SFRP5 treatment at $50(7.57 \pm 0.67 \%$ vs. $10.3 \pm 0.18 \%$; $\mathrm{P}<0.05), 100$ (7.1 $\pm 0.31 \%$ vs. $10.3 \pm 0.18 \% ; \mathrm{P}<0.01)$ and $200 \mathrm{ng} / \mathrm{ml}(6.7 \pm 0.51 \%$ vs. $10.3 \pm 0.18 \%$; P<0.01; Fig. 3$)$.

In the wound-healing assay, PDGF-BB significantly enhanced the SMC migration rate compared with the control group (51.4 \pm 3.99 vs. $24.8 \pm 2.21 ; \mathrm{P}<0.01)$, whereas SFPR5 significantly attenuated PDGF-BB-induced cell migration in a dose-dependent manner (51.4 \pm 3.99 vs. $39.1 \pm 3.05,38.6 \pm 3.33$ and $36.8 \pm 1.95$ at 50,100 and $200 \mathrm{ng} / \mathrm{ml}$, respectively $(\mathrm{P}<0.05$, $\mathrm{P}<0.0$ and $\mathrm{P}<0.01$, respectively; Fig. 4).

SFRP5 attenuates $\mathrm{H}_{2} \mathrm{O}_{2}$-induced $\mathrm{ROS}$ generation. For that PDGF-BB had no effect on the ROS production, we investigate 
A

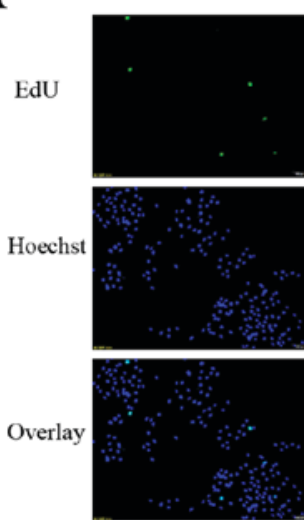

PDGF (ng/ml) SFRP5 (ng/ml)

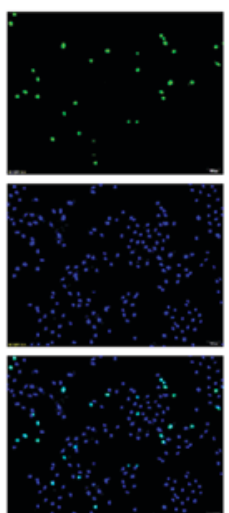

20
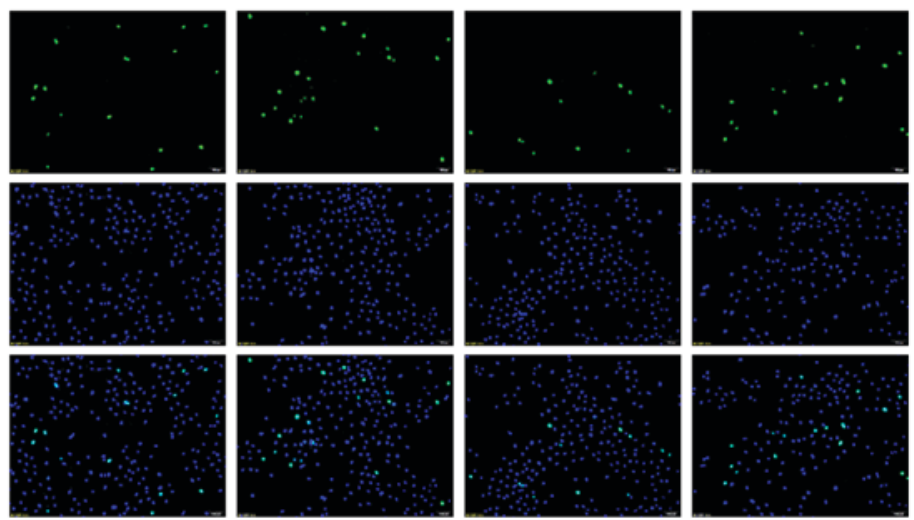

10

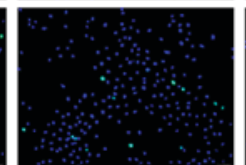

20

20
50

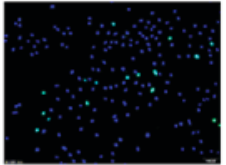

20 200

B

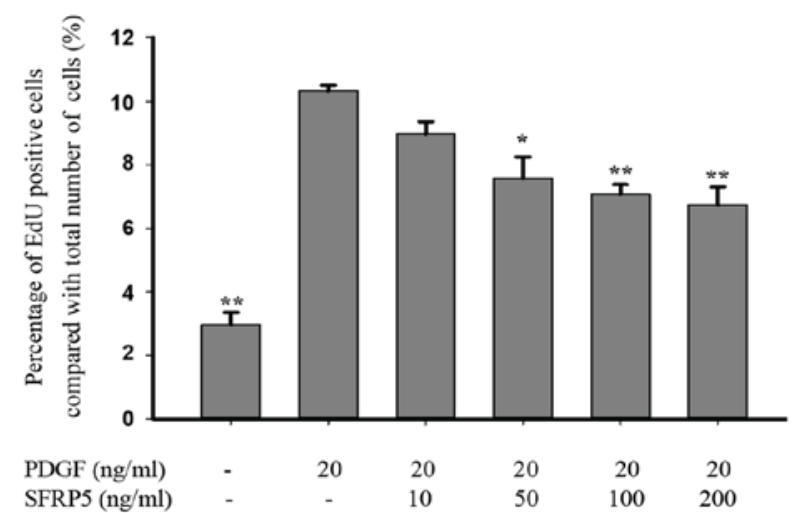

Figure 3. SFRP5 inhibits PDGF-BB-stimulated SMC proliferation. (A) Representative SMC proliferation among the different groups (magnification, x100). (B) Analysis of SMC proliferation rates. "P<0.05 and ${ }^{* *} \mathrm{P}<0.01$ vs. the $20 \mathrm{ng} / \mathrm{ml}$ PDGF-BB only group. SFRP5, secreted frizzled-related protein 5; SMC, smooth muscle cell; PDGF, platelet-derived growth factor; EdU, 5-ethynyl-2'-deoxyuridine.

the impact of SFRP5 on ROS generation induced by $\mathrm{H}_{2} \mathrm{O}_{2}$. ROS production in $\mathrm{H}_{2} \mathrm{O}_{2}$-stimulated SMCs was significantly increased when compared to the control group (22.1 \pm 3.31 vs. $0.57 \pm 0.12 ; \mathrm{P}<0.01)$, and this effect was markedly suppressed by SFRP5 (Fig. 5). Cells pretreated with $200 \mathrm{ng} / \mathrm{ml}$ SFRP5 had markedly decreases ROS production compared with $\mathrm{H}_{2} \mathrm{O}_{2}$-stimulated cells (11.5 \pm 1.4 vs. $\left.22.1 \pm 3.31 ; \mathrm{P}<0.01\right)$.

SFRP5 suppresses Wnt/ $\beta$-catenin signaling and $p 38$ expression. To elucidate the effects of SFRP5 on the Wnt/ $\beta$-catenin signaling pathway in SMCs, the expression of $\beta$-catenin, PCNA and cyclin D1 protein was investigated. PDGF-BB induced $\beta$-catenin and PCNA activation, which was inhibited by treatment with SFRP5 (Fig. 6). Additionally, mitogen-activated protein kinase (MAPK) phosphorylation was examined. Stimulation with PDGF-BB induced the rapid activation of $\mathrm{p} 38$ and $\mathrm{JNK} 1 / 2$ without affecting the total levels of these proteins (Fig. 7). The PDGF-BB-induced activation of p38 was significantly inhibited by SFRP5, while PDGF-BB-induced JNK1/2 activation was not significantly affected by pretreatment with SFRP5. No significant differences were observed in the total or phosphorylated levels of ERK1/2 protein following SFRP5 treatment (Fig. 7).

\section{Discussion}

It has previously been reported that increased proliferation, migration and inflammation of vascular SMCs contribute to aging-induced vascular dysfunction (2). In the present study, levels of SFRP5 were found to increase with age. In vitro, SFRP5 inhibited the PDGF-BB-induced proliferation and migration of SMCs, and also suppressed ROS generation. These findings suggest that SFRP5 may serve a beneficial role in vascular aging.

As a member of the SFRP family, SFRP5 secreted from white adipose tissue is important in embryonic development and organogenesis $(15,16)$. Additionally, SFRP5 was identified as an anti-inflammatory adipokine (5) and has been reported to be involved in the regulation of adipocyte metabolism and insulin resistance $(5,6,17,18)$. A number of studies have demonstrated that SFRP5 is associated with cardiovascular diseases, including vascular calcification (9), coronary artery disease (10), myocardial infarction (11) and myocardial hypertrophy (19). However, little is known about the role of SFRP5 in aging-related arteriosclerosis. Arterial ageing is a complex process, partly contributing to arteriosclerosis. In clinic, pulse wave velocity (PWV) especially carotid-femoral PWV, 
A
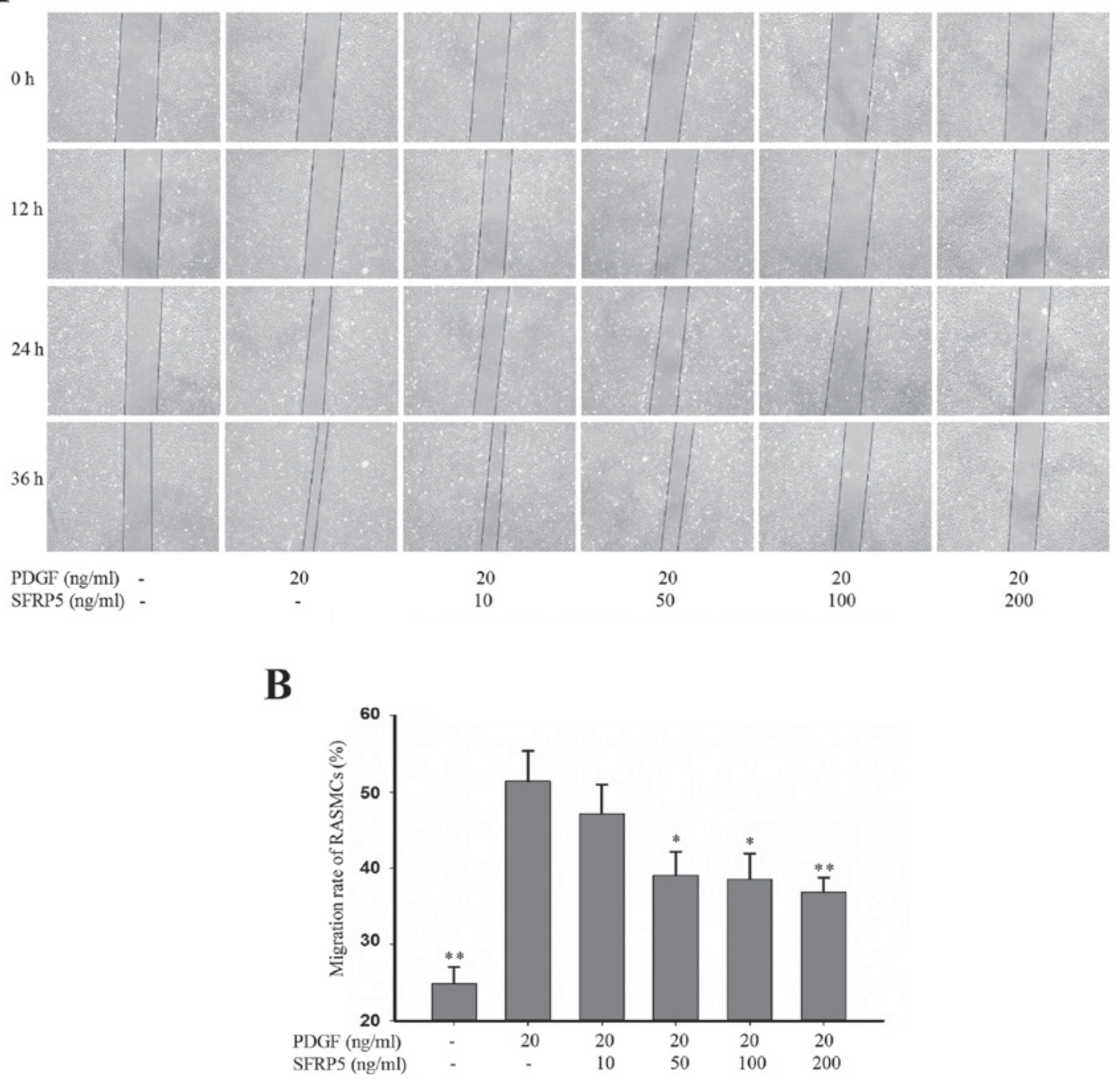

Figure 4. SFRP5 inhibits PDGF-BB-induced SMC migration. (A) Representative SMC migration among the different groups. Wound healing was monitored at $0,12,24$ and $36 \mathrm{~h}$ following wounding. (B) Analysis of SMC migration rates. ${ }^{*} \mathrm{P}<0.05$ and ${ }^{* *} \mathrm{P}<0.01 \mathrm{vs}$. the $20 \mathrm{ng} / \mathrm{ml} \mathrm{PDGF}-\mathrm{BB}$ only group. SFRP5, secreted frizzled-related protein 5; SMC, smooth muscle cell; RASMCs, rat aortic SMCs; PDGF, platelet-derived growth factor.

was accepted as a gold standard of arteriosclerosis and was calculated by dividing pulse wave traveled distance by transit time ( $\mathrm{PWV}=$ distance/time). As the arterial stiffness is mainly relevant with large arteries, we focused on the aorta to investigate the effect of SFRP5 on arterial stiffness. In the present study, plasma levels of SFRP5 increased with age in the overall population and in sex subgroups. Immunohistochemical analysis of rat aortas revealed a similar correlation between age and SFRP5 expression. Considering the anti-inflammatory function of SFRP5 and the fact that age is an independent risk factor for cardiovascular diseases, it was hypothesized that SFRP5 expression may increase with age via negative feedback and may serve a protective role in aging.

To verify the above hypothesis, the role of SFRP5 in vitro was investigated. For that SMC is the major cell type in the aorta and previous studies also indicated importance of SMC in arterial stiffness, SMC was used in our study. The results revealed that PDGF-BB increases the proliferation and migration of SMCs, which was consistent with previous studies (14). PDGF-BB, an isoform of PDGF, can bind to PDGF receptor- $\beta$ to induce receptor dimerization and autophosphorylation, thus initiating several signaling pathways that are essential for cell proliferation and migration. The PDGF-BB-induced increase in SMC proliferation and migration could be inhibited by pretreatment with SFRP5. Western blotting results revealed that SFRP5 inhibits PDGF-BB-induced expression of $\beta$-catenin and PCNA, as well as p38 phosphorylation. In addition, ROS generation is also involved in arterial ageing, while PDGF-BB had no effect on ROS production. Therefore, we used $\mathrm{H}_{2} \mathrm{O}_{2}$ for ROS detection, and find that SFRP5 can inhibit the ROS generation induced by $\mathrm{H}_{2} \mathrm{O}_{2}$.

Wnt proteins are cell signaling molecules that participate in various developmental events during embryogenesis and activate canonical or non-canonical Wnt signaling pathways, including the Wnt/ $\beta$-catenin, planar cell polarity and $\mathrm{Wnt} / \mathrm{Ca}^{2+}$ signaling pathways (20). $\beta$-catenin is a key downstream effector of the Wnt/ $\beta$-catenin signaling pathway, which is an evolutionarily conserved pathway implicated in cell proliferation $(21,22)$. $\beta$-catenin stabilization results in $\beta$-catenin translocation into the nucleus, followed by increased expression of proliferation-related genes (23). As SFRPs and Wnt proteins exhibit high homology in their cysteine-rich domains, SFRPs, including SFRP5, can 
A

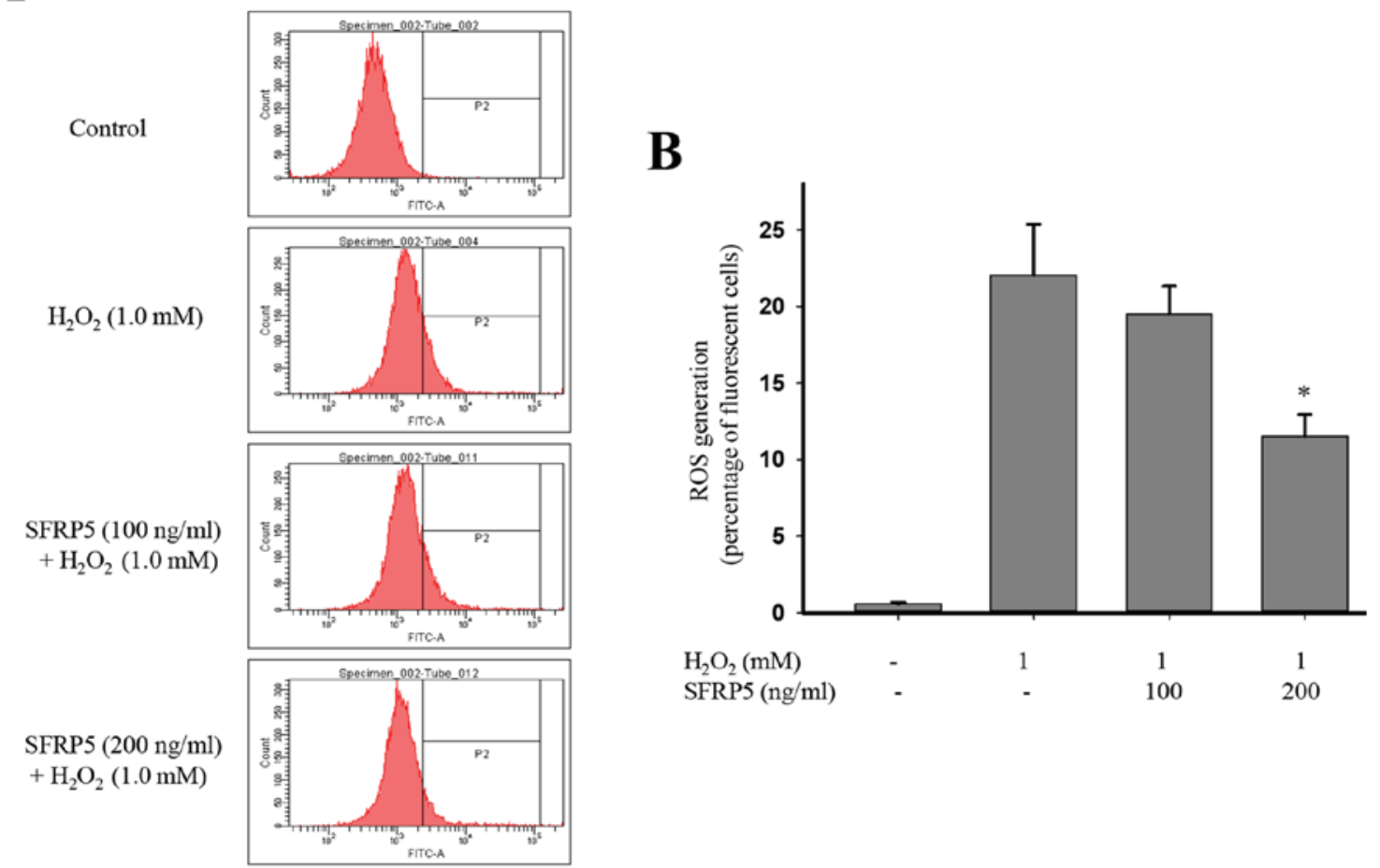

Figure 5. SFRP5 attenuates ROS generation in SMCs. (A and B) Representative ROS generation among the different groups: i) control group; ii) cells treated with $1.0 \mathrm{mM} \mathrm{H}_{2} \mathrm{O}_{2}$; iii) cells treated with $100 \mathrm{ng} / \mathrm{ml} \mathrm{SFRP5}$ and $1.0 \mathrm{mM} \mathrm{H}_{2} \mathrm{O}_{2}$; and iv) cells treated with $200 \mathrm{ng} / \mathrm{ml} \mathrm{SFRP5}$ and $1.0 \mathrm{mM} \mathrm{H}_{2} \mathrm{O}_{2}$. "P $<0.05 \mathrm{vs}$. $1.0 \mathrm{mM} \mathrm{H}_{2} \mathrm{O}_{2}$ group. SFRP5, secreted frizzled-related protein 5; SMC, smooth muscle cell; ROS, reactive oxygen species.

A

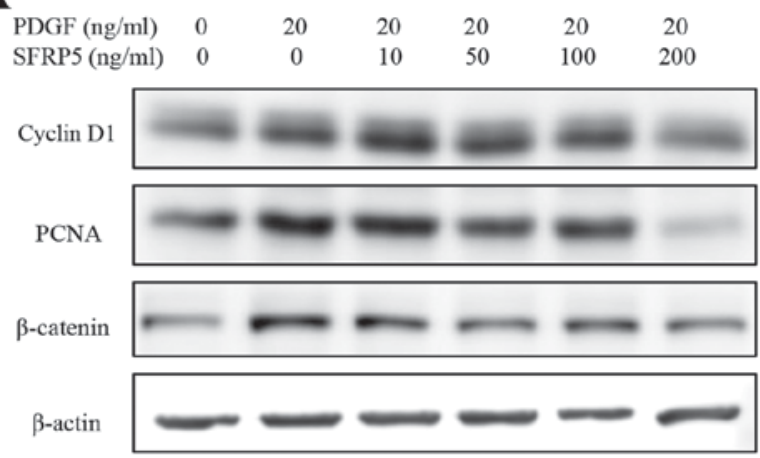

$\mathbf{C}$

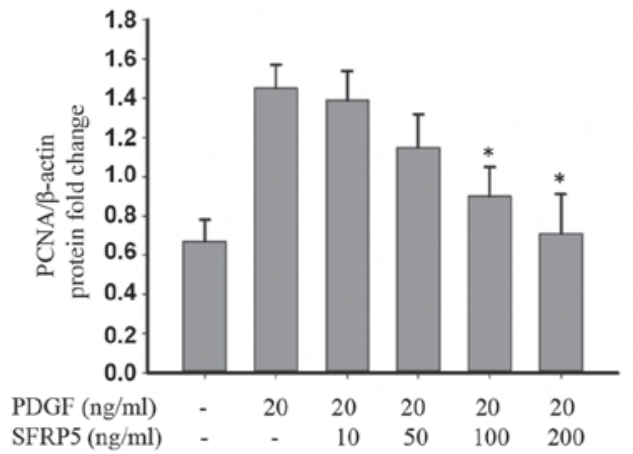

B

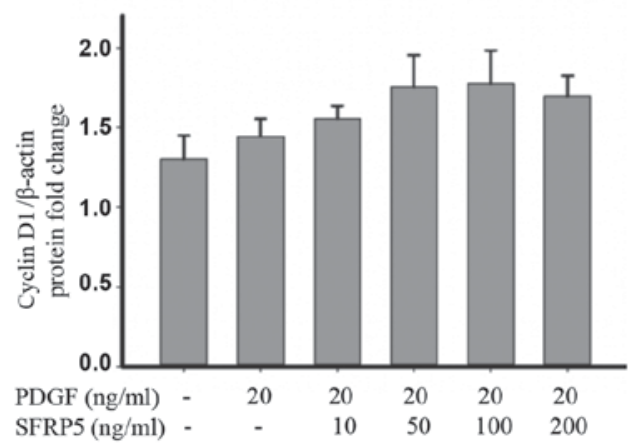

D

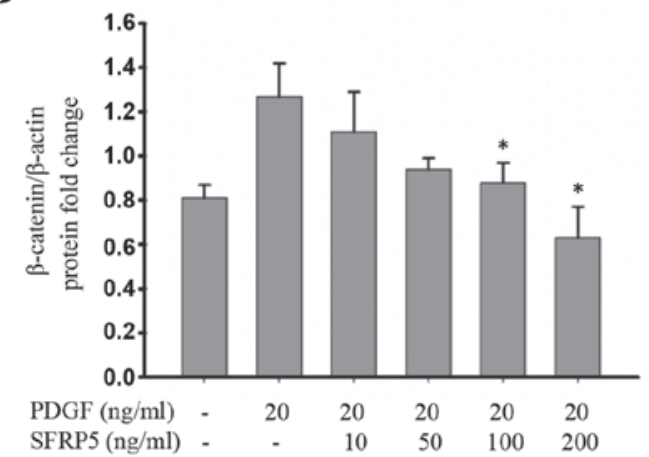

Figure 6. SFRP5 prevents PDGF-BB-induced Wnt/ $\beta$-catenin activation and suppresses PCNA expression. (A) Representative immunoblots of (B) cyclin D1, (C) PCNA and (D) $\beta$-catenin. (B-D) Quantitative analysis of the immunoblots in the different groups. Each band density was normalized to its own internal control. * P<0.05 vs. 20 ng/ml PDGF only group. SFRP5, secreted frizzled-related protein 5; PDGF, platelet-derived growth factor; PCNA, proliferating cell nuclear antigen. 
A

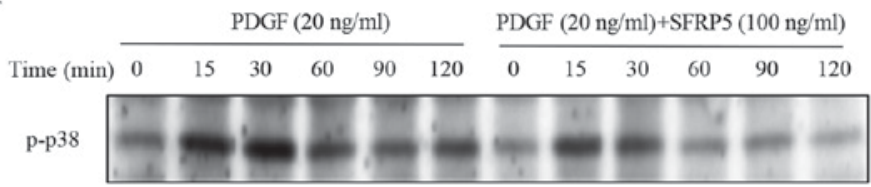

B
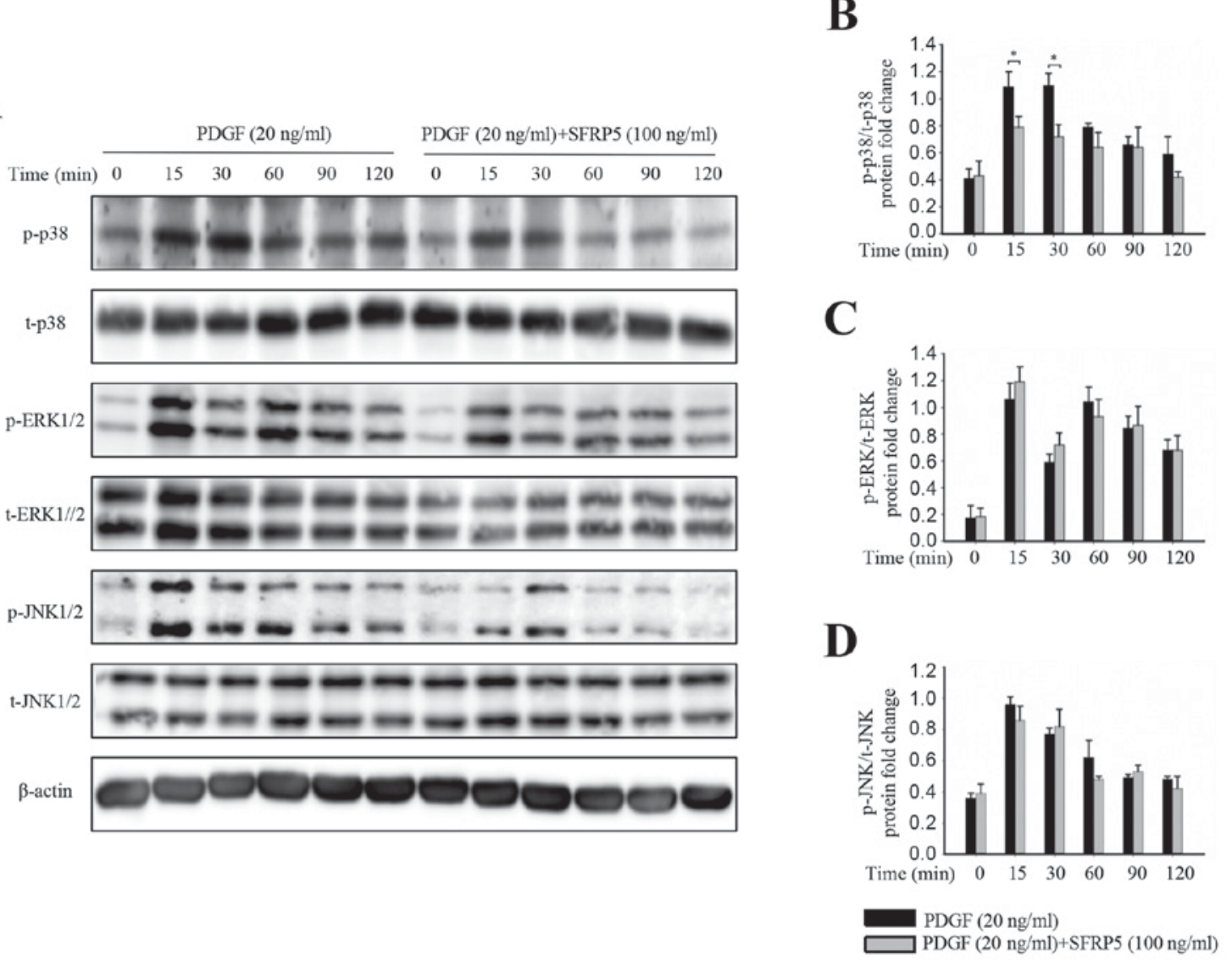

Figure 7. SFRP5 inhibits PDGF-BB-induced MAPK/p38 cell signaling. (A) Representative immunoblots of (B) p38, (C) ERK1/2 and (D) JNK phosphorylation, and a representative membrane showing their total protein levels. (B-D) Quantitative analysis of the immunoblot results among the different groups. Each band density was normalized to its own internal control. "P $<0.05$, as indicated. SFRP5, secreted frizzled-related protein 5; PDGF, platelet-derived growth factor; MAPK, mitogen-activated protein kinase; ERK, extracellular signal-regulated kinase; JNK, c-Jun N-terminal kinase; p-, phosphorylated; t-, total.

compete with the frizzled receptor to bind Wnt ligands and regulate the canonical and non-canonical Wnt signaling pathways (24-26). In the present study, it was observed that SFRP5 attenuated $\beta$-catenin expression in SMCs. Furthermore, PCNA expression was downregulated in SMCs. As MAPK signaling is known to increase cell proliferation and migration, the role of the MAPK signaling pathway in SMCs was investigated (27-29). PDGF-BB has been reported to affect cell proliferation via the activation of a number of intracellular signaling pathways, including the MAPK signaling pathway $(30,31)$. Our results suggest that only p38 phosphorylation was observed inhibited by SFRP5 treatment, while no significant differences in JNK, which is also a downstream target of the non-canonical Wnt signaling pathway, were observed. A previous study reported that SFRP5 attenuated JNK activation in macrophages and adipocytes (5). This discrepancy may be partly due to the different cell types used in the two studies and the complex crosstalk between the $\mathrm{Wnt} / \beta$-catenin and MAPK signaling pathways. Therefore, further studies are required in order to better understand the crosstalk between these complicated cells signaling pathways.

SFRP5 is an adipokine with anti-inflammatory effects, and so the majority of previous studies have focused on its role in metabolic syndrome-related diseases such as obesity and insulin resistance. However, few studies have been conducted to investigate the role of SFRP5 in CVDs, including vascular calcification, coronary artery disease and myocardial infarction. To the best of our knowledge, no other study focused on the role of SFRP5 in aging-related arteriosclerosis has been published to date. Therefore, the present study demonstrated for the first time that SFRP5 may serve a protective role in arterial aging.

In conclusion, the results of the present study suggest that SFRP5 may serve a beneficial role in arterial aging by inhibiting SMC proliferation, migration and inflammation via the Wnt/ $\beta$-catenin and p38/MAPK signaling pathways. Furthermore, the expression of SFRP5 may be an effective biomarker for CVDs, particularly arterial stiffening. However, further studies are required to confirm and verify the clinical significance and mechanism of SFRP5 in CVDs.

\section{Acknowledgements}

Not applicable.

\section{Funding}

The present study was supported by the National Nature Science Foundation of China (grant nos. 81670377 and 81300239). Dr Yuyan Lu was supported by Shanghai Tenth Hospital's Improvement Plan for NSFC. The Northern Shanghai Study was authorized and financially supported by the Shanghai 
Municipal Government (grant nos. 2013ZYJB0902 and 15GWZK1002).

\section{Availability of data and materials}

All data generated or analyzed during the present study are included in this published article.

\section{Authors' contributions}

YZ, JT and YX contributed to the conception and design of the study. JT, HJ, YL and CC performed experiments. JT, BB and SY analyzed the data and contributed to the writing of the manuscript, as well as approving the final manuscript. YZ and YX supervised the writing and revision of the manuscript.

\section{Ethics approval and consent to participate}

Written informed consent was obtained from all participants. The present study was approved by the Shanghai Tenth People's Hospital Ethics Committee (Shanghai, China). All animal procedures were carried out humanely in adherence with the animal experimental guidelines, and was approved, by the Animal Care and Use Committee of Shanghai Tenth People's Hospital (Shanghai, China).

\section{Patient consent for publication}

Written informed consent was obtained from all participants.

\section{Competing interests}

The authors declare that they have no competing interests.

\section{References}

1. North BJ and Sinclair DA: The intersection between aging and cardiovascular disease. Circ Res 110: 1097-1108, 2012.

2. Mistriotis P and Andreadis ST: Vascular aging: Molecular mechanisms and potential treatments for vascular rejuvenation. Ageing Res Rev 37: 94-116, 2017.

3. Ouwens DM, Sell H, Greulich S and Eckel J: The role of epicardial and perivascular adipose tissue in the pathophysiology of cardiovascular disease. J Cell Mol Med 14: 2223-2234, 2010.

4. Rajsheker S, Manka D, Blomkalns AL, Chatterjee TK, Stoll LL and Weintraub NL: Crosstalk between perivascular adipose tissue and blood vessels. Curr Opin Pharmacol 10: 191-196, 2010.

5. Ouchi N, Higuchi A, Ohashi K, Oshima Y, Gokce N, Shibata R, Akasaki Y, Shimono A and Walsh K: Sfrp5 is an anti-inflammatory adipokine that modulates metabolic dysfunction in obesity. Science 329: 454-457, 2010.

6. Mori H, Prestwich TC, Reid MA, Longo KA, Gerin I, Cawthorn WP, Susulic VS, Krishnan V, Greenfield A and Macdougald OA: Secreted frizzled-related protein 5 suppresses adipocyte mitochondrial metabolism through WNT inhibition. J Clin Invest 122: 2405-2416, 2012.

7. Koza RA, Nikonova L, Hogan J, Rim JS, Mendoza T, Faulk C, Skaf J and Kozak LP: Changes in gene expression foreshadow diet-induced obesity in genetically identical mice. PLoS Genet 2: e81, 2006.

8. Chatani N, Kamada Y, Kizu T, Ogura S, Furuta K, Egawa M, Hamano M, Ezaki H, Kiso S, Shimono A, et al: Secreted frizzled-related protein 5 (Sfrp5) decreases hepatic stellate cell activation and liver fibrosis. Liver Int 35: 2017-2026, 2015.

9. Deng D, Diao Z, Han X and Liu W: Secreted frizzled-related protein 5 attenuates high phosphate-induced calcification in vascular smooth muscle cells by inhibiting the Wnt/B-catenin pathway. Calcif Tissue Int 99: 66-75, 2016.
10. Miyoshi T, Doi M, Usui S, Iwamoto M, Kajiya M, Takeda K, Nosaka K, Nakayama R, Okawa K, Takagi W, et al: Low serum level of secreted frizzled-related protein 5, an anti-inflammatory adipokine, is associated with coronary artery disease. Atherosclerosis 233: 454-459, 2014.

11. Nakamura K, Sano S, Fuster JJ,Kikuchi R, Shimizu I, Ohshima K, Katanasaka Y, Ouchi N and Walsh K: Secreted frizzled-related protein 5 diminishes cardiac inflammation and protects the heart from ischemia/reperfusion injury. J Biol Chem 291: 2566-2575, 2016.

12. Ji H, Xiong J, Yu S, Chi C, Fan X, Bai B, Zhou Y, Teliewubai J, $\mathrm{Lu} \mathrm{Y,Xu} \mathrm{H,} \mathrm{et} \mathrm{al:} \mathrm{Northern} \mathrm{shanghai} \mathrm{study:} \mathrm{Cardiovascular} \mathrm{risk}$ and its associated factors in the Chinese elderly-a study protocol of a prospective study design. BMJ Open 7: e013880, 2017.

13. Travo P, Barrett G and Burnstock G: Differences in proliferation of primary cultures of vascular smooth muscle cells taken from male and female rats. Blood Vessels 17: 110-116, 1980.

14. Baumgartner HR and Hosang M: Platelets, platelet-derived growth factor and arteriosclerosis. Experientia 44: 109-112, 1988.

15. Satoh W, Matsuyama M, Takemura H, Aizawa S and Shimono A: Sfrp1, Sfrp2, and Sfrp5 regulate the Wnt/beta-catenin and the planar cell polarity pathways during early trunk formation in mouse. Genesis 46: 92-103, 2008.

16. Li Y, Rankin SA, Sinner D, Kenny AP, Krieg PA and Zorn AM: Sfrp5 coordinates foregut specification and morphogenesis by antagonizing both canonical and noncanonical Wnt11 signaling. Genes Dev 22: 3050-3063, 2008.

17. Lu YC, Wang CP, Hsu CC, Chiu CA, Yu TH, Hung WC, Lu LF, Chung FM, Tsai IT, Lin HC and Lee YJ: Circulating secreted frizzled-related protein 5 (Sfrp5) and wingless-type MMTV integration site family member 5a (Wnt5a) levels in patients with type 2 diabetes mellitus. Diabetes Metab Res Rev 29: 551-556, 2013.

18. Carstensen M, Herder C, Kempf K, Erlund I, Martin S, Koenig W, Sundvall J, Bidel S, Kuha S, Roden M and Tuomilehto J: Sfrp5 correlates with insulin resistance and oxidative stress. Eur J Clin Invest 43: 350-357, 2013.

19. Jin X, Guo B, Yan J, Yang R, Chang L, Wang Y, Miao C, Liu S, Zhang H and Li Y: Angiotensin II increases secreted frizzled-related protein 5 (sFRP5) expression through AT1 receptor/Rho/ROCK1/JNK signaling in cardiomyocytes. Mol Cell Biochem 408: 215-222, 2015.

20. Bovolenta P, Rodriguez J and Esteve P: Frizzled/RYK mediated signalling in axon guidance. Development 133: 4399-4408, 2006.

21. Nelson WJ and Nusse R: Convergence of Wnt, beta-catenin, and cadherin pathways. Science 303: 1483-1487, 2004.

22. Logan CY and Nusse R: The Wnt signaling pathway in development and disease. Annu Rev Cell Dev Biol 20: 781-810, 2004.

23. Clevers $H$ and Nusse $R$ : Wnt/ $\beta$-catenin signaling and disease. Cell 149: 1192-1205, 2012.

24. Kawano Y and Kypta R: Secreted antagonists of the Wnt signalling pathway. J Cell Sci 116: 2627-2634, 2003.

25. Suzuki H, Watkins DN, Jair KW, Schuebel KE, Markowitz SD, Chen WD, Pretlow TP, Yang B, Akiyama Y, Van Engeland M, et al: Epigenetic inactivation of SFRP genes allows constitutive WNT signaling in colorectal cancer. Nat Genet 36: 417-422, 2004.

26. Pećina-Šlaus N, Kafka A, Varošanec AM, Marković L, Krsnik Ž, Njirić $\mathrm{N}$ and Mrak G: Expression patterns of Wnt signaling component, secreted frizzled-related protein 3 in astrocytoma and glioblastoma. Mol Med Rep 13: 4245-4251, 2016.

27. Wang L, Zhu LH, Jiang H, Tang QZ, Yan L, Wang D, Liu C, Bian ZY and Li H: Grape seed proanthocyanidins attenuate vascular smooth muscle cell proliferation via blocking phosphatidylinositol 3-kinase-dependent signaling pathways. J Cell Physiol 223: 713-726, 2010.

28. Huang C, Jacobson K and Schaller MD: MAP kinases and cell migration. J Cell Sci 117: 4619-4628, 2004

29. Ono $\mathrm{K}$ and Han J: The p38 signal transduction pathway: Activation and function. Cell Signal 12: 1-13, 2000.

30. Dong LH, Wen JK, Miao SB, Jia Z, Hu HJ, Sun RH, Wu Y and Han M: Baicalin inhibits PDGF-BB-stimulated vascular smooth muscle cell proliferation through suppressing PDGFR $\beta$-ERK signaling and increase in p27 accumulation and prevents injury-induced neointimal hyperplasia. Cell Res 20: 1252-1262, 2010.

31. Iida M, Tanabe K, Kozawa $\mathrm{O}$ and Iida $\mathrm{H}$ : Differential effects of intravenous anesthetics on PDGF-BB-induced vascular smooth muscle cell migration. Cell Physiol Biochem 33: 1827-1837, 2014. 